\title{
English Language Learners
}

\author{
Danebeth T. Glomo-Narzoles \\ University of San Agustin, Philippines \\ dnarzoles@usa.edu.ph
}

Donna T. Glomo-Palermo

Iloilo City Community College, Philippines

dtgpalermo@gmail.com

DOI: http://doi.org/10.36892/ijlls.v2i3.380

\begin{tabular}{|c|c|}
\hline $\begin{array}{l}\text { Received: } \\
\text { 15/07/2020 }\end{array}$ & $\begin{array}{c}\text { Abstract } \\
\text { This study aimed to identify the effectiveness of an academic intervention, }\end{array}$ \\
\hline $\begin{array}{l}\text { Accepted: } \\
31 / 08 / 2020\end{array}$ & $\begin{array}{l}\text { tutorial classes in particular, as perceived by the students specifically in } \\
\text { improving their performance in their English subjects. This study made use of } \\
\text { the Tutorial Survey questionnaire adapted from Xixi Lu, et.al. (2003). The }\end{array}$ \\
\hline $\begin{array}{l}\text { Keywords: } \\
\text { Academic intervention; } \\
\text { Academic } \\
\text { performance; } \\
\text { English language; } \\
\text { Language learning; } \\
\text { Tutorials. }\end{array}$ & $\begin{array}{l}\text { questionnaire was distributed to the students who attended English language } \\
\text { tutorial classes in a private university. In order to substantiate the information } \\
\text { gathered through the questionnaire, interviews were also conducted to } \\
\text { selected participants. Results revealed that majority of students who availed } \\
\text { the English language tutorials were males. On the other hand, there were } \\
\text { more working students who attended the tutorials than the non-working } \\
\text { students. The students noted that the tutorial classes for their English subjects } \\
\text { were very effective. They perceived the tutorial classes and the faculty tutors } \\
\text { positively. Moreover, they were also very satisfied with the tutorial venue and } \\
\text { time. The students do not have further recommendations to improve the } \\
\text { university's tutorial classes. The students also added that these tutorials have } \\
\text { improved their listening, speaking, reading, and writing skills. For the other } \\
\text { academic interventions, the students suggested to have peer tutoring, } \\
\text { additional activities or enrichment materials through e-learning sites, and } \\
\text { video tutorials for those English subjects with lab components. }\end{array}$ \\
\hline
\end{tabular}

\section{INTRODUCTION}

Tutorial classes have been found to be efficient and effective in bridging the academic gaps of the students, especially those who are at risk (Ogina, 2010). However, do they have an impact on academic performance? Aspects of tutorial classes have generated a great deal of interests in the area of education.

According to Guerra-Martin (2014), tutoring is a formal process that involves as a relationship between a more experienced and knowledgeable person that plays a supportive role with a less experienced and knowledgeable person, so as to facilitate that person's career and personal development. Tutoring involves several attributes, such as coaching, assessing, facilitating, sponsoring, supporting, guiding, role modeling while also involving some interpersonal dynamics such as support, trust, a personal connection, career development, and student empowerment (Guerra-Martín, 2014).

Tutoring has been extensively researched and perceptions on what makes it effective is a topic of interest in various fields. Effective tutoring would suggest that this mode of 
instruction encompasses aspects regarding the tutorials, the tutors, the students, the venue and time, and type of tutorials, among others.

All these aspects are deemed to contribute to the effectiveness of holding tutorial classes so that the learners' academic needs are met. Tutors have an important role in the delivery of tutorial interventions. In a New Zealand university, a study was conducted to assess students' perceptions of tutors, some tutorial factors that contribute to their academic performance, and their overall tutorial experiences. Results showed that the students' learning environment, affirmative and practical feedback, and encouraging tutorials done by the tutors enhance student learning and led to greater levels of student satisfaction with their learning experiences in the university (Retna \& Kavana, 2009).

A similar study was done in a South African context which delved in the effectiveness of tutors. The participants, composed of university students, were diverse in terms of gender, race, ethnicity and geographical origin. The students rated some of the tutors positively noting that these tutors can discuss, ease understanding, and engage them far better than others. Hence, students with good tutors achieved higher academic gains. Moreover, students who more tutorials have 20\% improvement in their marks. Likewise, students whose tutorial attendance less had better academic performance than those who did not attend at all (McKay, 2016). A study from the Higher Education Quality Council of Ontario finds that test performance is improved by tutorial participation, but only when attending multiple tutorials throughout the term. Participating in one tutorial session did not improve the students' academic performance but attending more than one had a cumulative outcome. Hence, there is no significant effect on students' academic performance. The study showed that the traditional tutorial had a more positive effect on test results than the collaborative approach. The authors also highlight the possible benefits of the advance preparation built into the traditional model. However, students in the collaborative tutorials got better performance than voluntary online assignments (Menard, et al., 2015).

In tutoring, the tutor's goal is to get the students to learn on their own. The tutor acts as a guide without providing lectures unless absolutely necessary. A tutor should provide feedback but should not make specific corrections because they should lead the student to find the correct answer. On the other hand, English instructors are more responsible for learning and building the student's store of linguistic knowledge. The tutor provides detailed lesson plans and content targeted to the student's learning level and style. The tutor should also explain grammar rules, introduce new vocabulary and actively teach the student new concepts in the English language (Lubin, 2015).

In addition, Lubin (2015) underscored that tutorials can be beneficial for students and more rewarding for teachers. When teachers are aware of what the students need and how to address these, tutorials can produce more rapid results. By spending more time with a single teacher who knows the student and his/her abilities, the student will receive greater individualized lessons. In larger classes there are always students ahead of and behind the average. Those students either become bored or frustrated; either way those students don't receive the lessons they need to succeed in English. Those same students can be given better focused instruction in a one-on-one environment, advanced students can be challenged while lower-level students can be brought up to speed to compete with their peers. Aside from this, the teachers should also consider the students' individual differences and make adjustments based on the individual student. Steps in providing effective language tutorials include: build rapport, get warmed up, conversational exercises, reading and writing exercises, and homework.

The above-mentioned studies have not thoroughly identified students' perceptions on 
the effectiveness of tutorial classes based on various aspects such as the tutorials, the tutor, venue, and time. This study sought answers to the following questions:

1- What is the level of effectiveness of the English language tutorial classes in terms of the tutorial classes, the tutor, venue, and time?

2- How can tutorial classes be improved based on the students' perspective?

3- What other academic interventions do students prefer aside from tutorial classes?

This study is anchored on Vygotsky's Theory of the 'Zone of Proximal Development'. This theory puts forward that a learner can enhance his/her cognitive level and he/she is able to achieve this on his/her own capacity by responding to questions and learning with a 'more capable peer' or a teacher. The social context made available by communicating a task with a person, who has attained a higher degree of intellectual development, improves the students' the learner's cognitive growth by because of the expert peer (Vygotsky,1979). Tutorials are regarded as a necessary instructional strategy for the students because they undeniably aid those who are academically challenged and even those who wanted to further unleash their intellectual capacities a more capable person who is in this case, the teacher. One of the reasons why students attend the tutorials is that they cannot understand their lessons. One-on-one and face to face tutorials provide opportunities for the tutor's undivided attention. Each question is answered and each topic is explained, making everything clear to the tutee. The sessions also provide an avenue for students to work on their lessons in advance. Because the tutors understand the learning styles of their students, the young ones are taught appropriate techniques to help them grasp complicated or confusing concepts. In the process, they acquire good study habits, making them even better learners.

This study, in particular, focuses on tutorials as one of the academic interventions provided for English language learners in order to cope with difficulties in their English subjects. Moreover, since English skills are considered as academic language skills, tutorials are deemed to be efficient and effective in bridging the academic gaps of the language learners that would eventually lead them in attaining educational success. In the same way, this investigation supposes that tutorial classes give opportunities for the students to interact with their teachers, learn 'how to learn', and improve their academic performance. However, factors that could determine the effectiveness of these tutorials have to be explored as well.

\section{LITERATURE REVIEW}

A number of studies have been conducted to delve into the effectiveness of tutorials as an intervention for English language learners. According to Francis, et al. (2006), the mastery of academic language is undeniably the single most important determinant of academic success for individual students. While other correlates such as motivation, perseverance, and quantitative skills, among others play important roles in the learning process, the role that language plays in determining students' success with academic content has to be underscored. Proficient use of academic language, English in this case, is the key to learn the content. This lack of proficiency inhibits the learners to understand texts, affects their capacity to express through speaking and writing and can hinder their learning not only in English subjects but in all academic areas. The results of Veggel \& Amory's (2014) study revealed that that small group tutorials enhance students' confidence in Math and improve students' academic performance. Furthermore, student feedback on the tutorial programme provides a deeper insight into student experiences and the value students assign to the tutorials. 
Another study by Salazar et al. (2014) revealed that the tutoring program had a favorable impact on the students' classes, noting that the grades of students who had one-onone tutoring were statistically different from those of the students who did not attend tutorial classes. Tutorials are well-appreciated by the students too. Ogina's research (2010) noted that the students view their tutorial sessions as a worthwhile learning experience. Moreover, tutorial classes teach skills for students to face the examinations. It also provides a lot of benefits to students, such as getting the knowledge and having more confidence, as well as providing benefits to the school, because students are able to understand the lessons better. It can be viewed as a useful assisting tool for teaching students besides the normal school (Ogina,2010).

In a multicultural study conducted by Hof (2014), the results revealed that tutoring had a positive impact on academic performance in India, Israel, Italy and the United States. With tutoring, student's tests scores go up, their reading improves, and their ability to understand mathematics, language and social science concepts increases.

Students who avail of tutorial classes have higher success and retention rates than students who do not. They have not only improved their general study skills but also provide avenues for teacher-student engagement (San Bernandino Valley College, 2016).

For a tutoring program to be effective, it should be planned and adapted to the context and the needs and interests of the students (Lemus, et al.,2015). Tutors should also advise and orient individual or small group of students by providing special attention to imbibe good studying skills (Hernández, et al., 2013) Tutorials with these features could enhance the academic performance of the learners which eventually reduces the academic failure, retention and delays in the completion of their programmes (Velázquez-Sagahón, \& Rodríguez,2014).

Guerra-Martín (2014) studied the suitability of tutoring strategy, the timing, the tutors, and the perceptions of students on how tutorials improved their personal and educational endeavours. The study found out that the students believed that the information received from the tutors were adequate, contents were adapted to their needs, and that they would surely recommend the tutorials to the other students. The leaners also noted that their tutors made a great effort to help them because they had properly planned and prepared to carry out the said activity. Hence, they were satisfied with the tutoring. On the aspect of the timing, the students regarded it as adequate. Lastly, the students perceived that the tutorials helped them in their time management, study skills, and most importantly, the improvement of their academic performance.

The study of Sharif et al. (2012) revealed that the tutorial program in a Malaysian university utilized higher level, ESL students, as peer tutors for lower level learners. The tutees performed reflexive activities based upon their life experiences. The researchers found that activities in which the learner's real-life experiences were highlighted were most successful. Sessions in which the tutor/tutee was nearly the same age and shared the same first language were also deemed successful. In addition, sessions have provided a friendly environment which improved the speaking skills of all the participants. It was also noted that the benefits of tutoring go beyond the classroom to aspects such as integration into an English speaking environment and increased employment opportunities in the future. 
The research of Craddock (2014) revealed that one-on-one tutoring is a useful pedagogical tool. Tutoring sessions are ideal since they allow verbal exchanges needed to increase both input and output of the English language learners. In the study, one-on-one tutoring sessions were audio-recorded to analyze what target language features were focused on during the tutoring sessions and what kinds of interactions occurred during the tutoring sessions, among others. Findings showed that the time spent on target language feature talk as opposed to other kinds of interactions.

Findings of the study conducted by Marieswari \& Prema (2016) indicate that the experimental group students exhibited a remarkable improvement in learning who received the content through peer tutoring than the control group students who were taught by the researcher through traditional way of teaching. Tutorials were deemed to promote fruitful learning; hence, the teacher can optimize the tutoring sessions which create a friendly environment in the school, where there is no threat and no rejection. The tutorial classes develop an interest in learning English language among tutors and tutees. The responsibility of the teachers is to adopt new techniques of teaching to let students understand the concepts.

Another study of Law, et al. (2015) aimed to discover the development of self-efficacy and interest in learning English through tutoring sessions. After completing 12 English tutoring classes of teaching experience, the undergraduate students were invited to attend a focus group interview. Results revealed that there was an increase in the sources of selfefficacy to the subjects in learning English, an increase in self-efficacy in the subjects' English learning, and a greater interest in learning English. Almarzouqi (in Marieswari \& Prema, 2016) has conducted qualitative research on peer tutoring which aimed to evaluate the English language peer tutoring programme. Benefits of tutors included learning through teaching and becoming more responsible while doing something worthwhile to help others. Benefits of tutees included improved levels of self-confidence and English language aptitude.

However, according to Fouche (2007), attending tutorials does not seem to have had a significant influence on students' improved performance on the standardized academic literacy test. However, tutorials have an effect on improving students' academic writing in ways not registered by the standardized test.

Apparently, it is imperative to determine the effectiveness of the selected education institutions' English language tutorial program in terms of the tutorials, the tutors, time and the venue. It is equally significant as well to determine the students' perceptions regarding the impact of tutorials not only in their English subjects but in their academic performance as a whole. Information from this current investigation will be significant in assessing the other interventions done or to be done in order to aid English language learners.

\section{METHODOLOGY}

A mixed-method, composed of quantitative and qualitative data was utilized in this research. According to Wisdom \& Cresswell (2013), this method is used to integrate a more complete data rather than doing a separate data collection and analysis of both quantitative, which is close-ended, and qualitative, which is open-ended, data than do separate quantitative and qualitative data collection and analysis. 
This study made use of the Tutorial Survey questionnaire adapted from Xixi Lu, et.al. (2003). The said questionnaire is composed of five sections, namely: the tutorials, the tutor, the student's experiences in the tutorial class, venue, and time. The statements were rated by a five-point Likert scale ( $1=$ Strongly Disagree to $5=$ Strongly Agree). The participants were chosen through convenience sampling (Fraenkel, et al., 2012). This paved way to access students who were available for the study, particularly those who availed the free tutorial classes in the university.

To substantiate the information gathered through the questionnaire, interviews were also conducted to selected participants. Upon retrieval of the accomplished instruments, the data were processed and interpreted according to the requirements of the problems.

For descriptive statistics tools, mean and standard deviation were used.

\section{RESULTS}

\subsection{Students' Perceptions Regarding the Tutorial Classes}

Table 1 presents the students' perceptions regarding the tutorial classes. The students noted that the tutorial classes are "very effective" because of the following indicators: 1.they covered key areas and ideas that were linked to the class lectures; 2 . were well-planned and structured; 3. encouraged students to prepare for the summative exams properly; 4. contents were adapted to their needs, improved their academic performance; and 5. covered key areas and ideas that were linked to the class lecture. Results were corroborated by research results of Veggel and Amory (2014), Salazar, et al. (2017), Ogina (2010), Hof (2014), and Lemus et.al (2015) that tutorial classes improved students' academic performance, added up to their over-all worthwhile learning experiences, and eventually reduced the academic failure, retention and delays in the completion of their programmes.

Moreover, the results are further supported by the students' answers during the interviews and these include 1. "The tutorial lessons were very effective; I almost failed my Technical Writing course but because of the tutorial sessions given by my teacher, I passed". The tutorial class did not only help me in improving my writing skills but it also helped a lot in making me more confident to use the English language; 2. "The tutorial classes are tailored to my needs; hence, I easily understand my grammar lessons. My tutor has contextualized the lessons, gave examples I can easily relate with, and provided a number of activities and exercises that undeniably enhanced my grammar skills. 3. "The lessons in my tutorial classes prepared me for major exams. My teacher was patient enough to provide me with reading materials which were very effective in developing my comprehension skills".

Table 1. Students' Perceptions Regarding the Tutorial Classes

\begin{tabular}{|lcc|}
\hline The tutorial classes... & Mean & $\begin{array}{c}\text { Descriptive } \\
\text { Interpretation }\end{array}$ \\
\hline $\begin{array}{l}\text { covered key areas and ideas that were linked to the } \\
\text { class lectures }\end{array}$ & 4.76 & Very effective \\
\hline were well-planned and structured & 4.70 & Very effective \\
\hline $\begin{array}{l}\text { encouraged students to prepare for the summative } \\
\text { exams properly }\end{array}$ & 4.74 & Very effective \\
\hline
\end{tabular}




\begin{tabular}{|lcc|}
\hline contents were adapted to my needs & 4.74 & Very effective \\
\hline improved my academic performance & 4.50 & Very effective \\
\hline Average Mean & 4.69 & Very effective \\
\hline
\end{tabular}

\subsection{Students' Perceptions Regarding the Faculty Tutors}

Table 2 shows the students' perceptions regarding faculty tutors. The students believe that: the tutors helped them in all the difficulties that they have encountered in their academic life; they were interested in the students' academic progress; recognized that students differ in their needs, concerns, and interests; gave the students confidence in answering their exams; and showed concern and made great efforts in helping the students. Hence, the faculty were "very effective" in the delivery of the tutorial lessons.

The results are confirmed by Guerra-Martín (2014), Retna and Kavana (2009), and McKay (2016) which stressed that tutors who also coach, support, guide, trust, and understand the students surely enhance their learning and lead them to higher satisfaction with the learning experiences.

When asked about their perceptions about the faculty tutors, the students' responses were: 1 . "My teacher makes constant follow-up regarding my progress and I appreciate that"; 2. "I enjoy my tutorial sessions because my teacher makes me feel that I am important. She shows her utmost concern and this motivates me to study harder so I will pass the course"; 3. "I am a working student and sometimes, I skip my class because of workplace issues. However, I can cope with my lessons easily because of the help, support, and encouragement of my teacher"; 4. "My teacher is very supportive. She did not only help me in improving my English language skills but also in my personal life. I almost decided to drop the class because I have difficulties understanding complex lessons and I have personal problems too. She made me believe that I can handle everything if I will try my best. I did and I passed the dreadful subject".

Table 2. Students' Perceptions Regarding the Faculty Tutors

\begin{tabular}{|c|c|c|}
\hline My tutor... & Mean & Descriptive Interpretation \\
\hline $\begin{array}{l}\text { helped me in all the difficulties I have } \\
\text { encountered in my academic life }\end{array}$ & 4.70 & Very effective \\
\hline was interested in my academic progress & 4.60 & Very effective \\
\hline $\begin{array}{l}\text { recognized that students differ in their needs, } \\
\text { concerns, and interests }\end{array}$ & 4.54 & Very effective \\
\hline $\begin{array}{l}\text { gave me the confidence to answer exam } \\
\text { questions }\end{array}$ & 4.68 & Very effective \\
\hline $\begin{array}{l}\text { showed concern and made a great effort to help } \\
\text { me }\end{array}$ & 4.66 & Very effective \\
\hline
\end{tabular}



Average Mean
4.64
Very effective

\subsection{Students' Perceptions Regarding the Tutorial Classes}

Table 3 indicates the students' perceptions regarding the tutorial classes. Over-all, the students perceive the tutorial classes to be "very effective". They looked forward to tutorials, are satisfied and truly enjoyed with the tutoring, would recommend tutorials to other students who are at risk and those who would like to improve their marks, helped them enhance their confidence and communication skills. These have been supported by the results of the studies conducted by the Hong Kong Examinations and Assessment Authority (2017), the San Bernandino Valley College (2015), and Guerra-Martín (2014) which underscored that tutorial classes improve their time management, study skills, and most importantly, their academic performance. Through tutorials, academic failure, retention problems, and delays in the completion of the students' programmes are lessened Students' responses during interviews also support the findings. There answered include 1. "At first, I was hesitant to attend my language tutorial sessions because I thought all the while that these are just for the academically-challenged students. I tried to attend one session and from then on, I have always wanted to attend the tutorial class because of its positive impact to my grades"; 2. "I was encouraged by my friends to attend the tutorials and I appreciate all the knowledge that I have learned through the sessions. I was able to improve my language skills too through interaction with my teacher"; 3. "I am shy to ask my teacher during the class. What I appreciate during tutorial lessons is that I feel comfortable asking my teacher about some clarifications regarding the lessons".

Table 3. Students' Perceptions Regarding the Tutorial Classes

\begin{tabular}{|c|c|c|}
\hline As a student... & Mean & Descriptive Interpretation \\
\hline I looked forward to tutorials & 4.56 & Very effective \\
\hline I am satisfied and I truly enjoyed the tutoring & 4.62 & Very effective \\
\hline I learned a lot from tutorials & 4.62 & Very effective \\
\hline $\begin{array}{l}\text { I would recommend tutorials to other students } \\
\text { who are at risk and those who would like to } \\
\text { improve their marks }\end{array}$ & 4.64 & Very effective \\
\hline $\begin{array}{l}\text { I believe that tutorials helped me enhance my } \\
\text { confidence and communication skills }\end{array}$ & 4.64 & Very effective \\
\hline Average Mean & 4.62 & Very effective \\
\hline
\end{tabular}

4.4. Students' Perceptions Regarding the Tutorial Venue

Table 4 indicates the students' perceptions regarding the venue of the tutorial classes. In general, the students were "very satisfied "about the venue because it has proper lighting and ventilation, spacious enough to accommodate students, and is conducive to learning. The 
research of Guerra-Martín (2014) also revealed that the students' satisfaction with the venue helped them to be comfortable in their tutorial sessions.

During the interviews, the students gave the following responses:1. "The tutorial sessions were conducted in a spacious consultation room in the University. Sometimes, the teacher also makes use of his or her as the tutorial venue" 2. "I have no negative issues with the venue. It is very convenient for me".

Table 4. Students' Perceptions Regarding the Tutorial Venue

\begin{tabular}{lcc}
\hline The tutorial venue & Mean & Descriptive Interpretation \\
\hline with proper lighting and ventilation & 4.46 & Very satisfied \\
\hline spacious enough to accommodate the student/s & 4.36 & Very satisfied \\
\hline conducive to learning & 4.54 & Very satisfied \\
\hline Average Mean & 4.45 & Very satisfied \\
\hline
\end{tabular}

4.5. Students' Perceptions Regarding the Tutorial Time

Table 5 indicates the students' perceptions regarding the time of the tutorial classes. Over-all, the students were "very satisfied" with the tutorial time. This is supported by Guerra-Martín's research findings in which the students also regarded the tutorial timing as adequate

When interviewed, these were the students' answers: 1. "My teacher willingly conducts tutorial classes during her tutorial or consultation hours;" 2. "I can always adjust to the availability of my teacher. Usually, tutorial sessions are scheduled during her consultation hours and I am happy with that"; 3." Most of the teachers make themselves available to conduct tutorial sessions".

\section{Table 5. Students' Perceptions Regarding the Tutorial Venue}

\begin{tabular}{lcc}
\hline The tutorial time & Mean & Descriptive Interpretation \\
the tutor is always available for tutorial & 4.52 & Very satisfied \\
\hline time preference is considered & 4.48 & Very satisfied \\
\hline enough time for tutorial & 4.60 & Very satisfied \\
Average Mean & 4.53 & Very satisfied \\
\hline
\end{tabular}

\subsection{Other Suggestions/Recommendations of the Students that Could Improve} English Language Tutorial Classes

When asked about their suggestions/recommendations that could improve tutorial classes, the students provided the following responses: 1. "I don't have any issues with the University's tutorial classes. I am thankful actually that these are provided for free; 2 . "The 
teacher accommodate one-on-one or small group tutorials and I am happy about this; 3. "I am happy and satisfied with the tutorial classes provided"; 4. "This mechanism is already in place and I don't want to change anything about it"; 5. Thank you, tutors, for the assistance in my academic life. These tutorial classes really helped me a lot".

\subsection{Other Academic Interventions Students Prefer Aside from Tutorial Classes}

When asked about academic interventions students prefer aside from tutorial classes, the students provided the following responses: 1. "If the University can introduce peer tutoring, it would be much appreciated; 2. Additional activities or enrichment materials can be provided through e-learning platforms; 3 . Video tutorials may be considered by the university especially for those courses with lab components".

\section{CONCLUSIONS}

The students noted that the tutorial class as an academic intervention, conducted by the university, is very effective. The students perceived the tutorial classes and the faculty tutors positively. Moreover, they were also very satisfied with the tutorial venue and time. The students do not have suggestions/recommendations to improve tutorial classes. Instead, they were thankful to the tutors for assisting them in their academic life. For the other academic interventions that students refer aside from tutorial classes, the students suggested having peer tutoring, additional activities or enrichment materials through educational platforms, and video tutorials for those courses with lab components.

\section{RECOMMENDATIONS}

Since the tutorial classes were perceived by the students to be very effective, teachers may maintain the said academic intervention and find more innovative ways to make tutorial classes more interesting and enjoyable. Even though the students do not have suggestions/recommendations to improve tutorial classes, the university administrators may continue to look for possible ways to enhance the existing tutorial program. In addition, other forms of tutorials such as peer tutoring, blended learning with the use of technological platforms may be introduced. All these could also be used not only in the tutorial sessions but also in the classroom English language teaching-learning process. Lastly, future research may be conducted in order to assess the effectiveness of tutorial classes in other subjects.

\section{REFERENCES}

Craddock, H. (2014). Tutoring ESL Students for Improvements in Language Skills. Theses, Dissertations and Capstones. Paper 835.

Fouche, I. (2007).The Influence of Tutorials on the Improvement of Tertiary Students' Academic Literacy. Per Linguam. Retrieved from https://pdfs.semanticscholar.org.

Hof, S. (2014). Does private tutoring work? The effectiveness of private tutoring: A nonparametric bounds analysis. Education Economics, 22(4), 347-366.

Hong Kong Examinations and Assessment Authority. (2017). Is attending tutorial classes a new trend?. Retrieved from http://www.hkeaa.edu.hk

Fraenkel, J. R., Wallen, N. E., \& Hyun, H. H. (2012). How to Design and evaluate research in education (8 ed.). New York: McGraw-Hill. 
Guerra-Martín, M. D. (2014). Tutoring as a way of achieving employability for nursing students at the University of Seville. Procedia-Social and Behavioral Sciences, 139, 479-486.

Hernandez, Y., Martínez, J. C., \& Carranza, C. I. (2013). Institutional Tutoring Program: a strategy for raising standards of achievement in an educational institution. Acta Universitaria, 23(1), 31- 36.

Law, Q. et al. (2015). Enhancement of Self-efficacy and Interest in Learning English of Undergraduate Students with Low English Proficiency through a Collaborative Learning Programme. American Journal of Educational Research. Retrieved from http://pubs.sciepub.com

Lemus, L. A., Torres, F. S., Serrano, M., \& Gúzman, G. (2015). La tutoría: eje fundamental para mejorar el rendimiento académico de alumnos de nivel superior. Innovación Educativa, 15(67), 89-110.

Lubin, M. (2015). The Teacher's Handbook for Great One-on-one ESL Lessons. Retrieved fromhttps://www.fluentu.com

Marieswari, M. \& Prema, N. (2016). Effectiveness of Peer Tutoring in Learning English among Tutors and Tutees of Class VIII Students in Kancheepuram DT. English Language Teaching.Retrieved from https://files.eric.ed.gov/fulltext/EJ1115729.pdf

Menard,K. Payne, A. ,Kotlyachkov, O. \& Minaker, B. (2015) The Effectiveness of Tutorials in Large Classes: Do they matter?. Retrieved from http://www.heqco.ca.

McKay, T.M. (2016).Do Tutors Matter? Assessing the Impact of Tutors on First-Year Academic Performance at a South African University.Journal of Student Affairs in Africa, v4 n1 p51-62 2016. 12 pp.

Ogina, T. (2010).Experiences of tutorial sessions as learning support for distance education students. NADEOSA Conference. DOI: 10.13140/2.1.1660.4965.

Retna,K. \& Kavana, R. (2009). Tutors and tutorials: students' perceptions in a New Zealand University. Journal of Higher Education Policy and Management .Volume 31, Issue 3. https://doi.org/10.1080/13600800902974336

Salazar, O.C., López, R., Garcia, J., \& Medina, I. Monitoring the Results of the Tutoring Program in Its Face-to-Face and Virtual Modalities on the Academic Achievement of Students at a Mexican University. International Journal of Higher Education, v6 n2 p169-181 2017. 13 pp. Retrieved from https://www.ncbi.nlm.nih.gov.

San Bernandino Valley College. (2016). The Effects of Tutoring on Academic Performance.Retrieved from www.valleycollege.edu.

Wisdom, J. \& Creswell, JW. (2013). Mixed Methods: Integrating Quantitative and Qualitative Data Collection and Analysis While Studying Patient-Centered Medical Home Models. Rockville, MD: Agency for Healthcare Research and Quality. AHRQ Publication No. 13-0028-EF

Veggel, A. and Amory, J. (2014).The Impact of Math Support Tutorials on Mathematics Confidence and Academic Performance in a Cohort of HE Animal Science Students Peer. 2014; 2: e463.

Vygotsky, L. (1979). Mind in Society: The Development of Higher Psychological Processes. M. Cole et al. (Eds) (Harvard, MA: Harvard University Press). 
Velázquez-Sagahón, F-J, \& Rodríguez de la Osa, H-E. (2014). Design and implementation of subject tutoring in the degree program in administrative information systems of the Guanajuato University. Revista Iberoamericana de Educación Superior, 5(14), 41-54.

Xixi, L. (2003).A Survey of Tutorial Preparation and Participation. CDTL Brief. Vol. 6, No. 10 